\title{
LA SUSPENSIÓN DEL MANDATO PARLAMENTARIO Y SUS CONSECUENCIAS A LA LUZ DE LAS ÚLTIMAS EXPERIENCIAS
}

The suspension of the parliamentary mandate and its consequences in the light of the latest developments

\author{
ESPERANZA GÓMEZ CORONA \\ Universidad de Sevilla \\ gcorena@us.es
}

Cómo citar/Citation

Gómez Corona, E. (2020).

La suspensión del mandato parlamentario y sus consecuencias

a la luz de las últimas experiencias.

Revista de Estudios Políticos, 190, 199-226.

doi: https://doi.org/10.18042/cepc/rep.190.07

\section{Resumen}

En este trabajo reflexionamos sobre la suspensión del mandato parlamentario, una figura que entraña una limitación del derecho fundamental a la participación política de los representantes y a su vez incide en la composición de las Cámaras parlamentarias tal y como fueron configuradas por la voluntad popular.

Nos centraremos en las causas previstas en los distintos reglamentos parlamentarios de nuestro país y, sobre todo, en los efectos que provoca, prestando una atención especial a su extensión a las prerrogativas parlamentarias.

\section{Palabras clave}

Suspensión; mandato representativo; prerrogativas parlamentarias; derecho fundamental a la participación política.

\section{Abstract}

In this paper we will reflect on the suspension of the parliamentary mandate, a figure that implies a limitation of the fundamental right to political participation of 
Parliamentary representatives and, at the same time, affects the composition of the Parliamentary Houses as configured by the popular will.

We will focus on the causes for suspension foreseen in the different Parliamentary Regulations in Spain and, above all, on the effects such suspension causes, paying special attention to its extension to include Parliamentary prerogatives.

\section{Keywords}

Suspension; parliamentary mandate; parliamentary prerrogatives; fundamental right to political participation. 


\section{SUMARIO}

I. PLANTEAMIENTO. II. LA SUSPENSIÓN EN DERECHO PARLAMENTARIO ESPAÑOL: DEFINICIÓN Y CAUSAS: 1. De qué hablamos cuando hablamos de suspensión. 2. Tipos de suspensión en función de la causa: 2.1. La situación de los representantes electos. 2.2. Suspensión que trae causa en un proceso judicial. 2.3. La suspensión disciplinaria. III. SUSPENSIÓN Y PRERROGATIVAS PARLAMENTARIAS. IV. CONCLUSIONES. BIBLIOGRAFía.

\section{PLANTEAMIENTO}

En los últimos tiempos, el conflicto catalán está poniendo sobre la mesa cuestiones que entre nosotros parecían pacíficas, como el alcance de la inmunidad parlamentaria, a la vez que nos obliga a replantear otras totalmente nuevas, como la posibilidad de celebrar la sesión de investidura de manera telemática, sin que la persona candidata se encuentre físicamente en la sesión plenaria ${ }^{1}$.

Junto a ellas, institutos como la suspensión del ejercicio del mandato parlamentario y su extensión o no a las prerrogativas parlamentarias alcanzan otra dimensión y aconsejan una nueva mirada que, sin embargo, no pierda de vista el fin último al que responde su reconocimiento por el ordenamiento jurídico.

La suspensión entraña una limitación del derecho fundamental a la participación política de los representantes, por lo que debe ser reconocida y aplicada con suma cautela. Además, la ausencia de un mecanismo de sustitución de los parlamentarios suspendidos provoca inevitablemente una alteración en la composición de la Cámara tal y como surgió de las urnas, lo que puede acabar incidiendo a la postre en la conformación de la voluntad popular. Solo este elemento de por sí, debería bastar para cuestionar la regulación de los supuestos de hecho que dan lugar a la misma en algunos reglamentos parlamentarios de nuestro país.

1 SSTC 17/19, de 11 de febrero y 45/19, de 27 de marzo. 
En las páginas que siguen reflexionaremos sobre la suspensión de la condición de representante, figura que entre nosotros ha recibido una atención minoritaria, con alguna excepción, y que en el último año ha adquirido una actualidad inusitada como consecuencia del procesamiento y posterior condena de varias personas que ostentaban la condición de representante, algunas de los cuales además concurrieron y obtuvieron escaño en las elecciones generales de 28 de abril o en las europeas del 26 de mayo de 2019.

\section{LA SUSPENSIÓN EN DERECHO PARLAMENTARIO ESPAÑOL: DEFINICIÓN Y CAUSAS}

\section{DE QUÉ HABLAMOS CUANDO HABLAMOS DE SUSPENSIÓN}

Podríamos definir la suspensión como «aquella pérdida transitoria de alguno o todos los derechos y deberes que integran el estatuto jurídico de parlamentario, por mor de sentencia judicial o de una medida disciplinaria impuesta por los órganos competentes de las Cámaras, al haber violado uno de sus miembros, las normas de conducta reglamentariamente exigidas» (Caamaño, 1991: 231, 232).

Esta definición tiene que ser completada con la previsión del art. 384 bis de la Ley de Enjuiciamiento Criminal (LECr), que establece la suspensión de cargo público en un momento procesal anterior a la sentencia. Y además, atendiendo a la previsión presente en casi todos los reglamentos parlamentarios de nuestro país, con la suspensión decretada por la propia Cámara ante la imposibilidad del representante de ejercer su cargo, ya sea porque una sentencia condenatoria se lo impide o porque lo hace la situación de prisión provisional en que se pueda encontrar.

Este supuesto es diferente del que se produce cuando un parlamentario o parlamentaria electo no perfecciona su condición, no llegando en consecuencia a gozar de todos los derechos y deberes que el cargo representativo comporta. En sentido estricto, no hay suspensión de una condición previa, sino que el goce de todos los derechos y facultades queda pendiente de la posterior adquisición de la condición plena de representante.

Esta situación parece adquirir un carácter definitivo cuando se dejan pasar tres sesiones sin cumplir los requisitos establecidos, momento en el que la persona representante quedaría suspendida en el ejercicio de sus derechos y facultades, y analizaremos si también de las prerrogativas, como establecen un buen número de reglamentos parlamentarios en nuestro país.

En estas páginas vamos a ocuparnos de todas estas formas de suspensión, como figura que entraña una interrupción en el ejercicio del cargo representativo 
por tiempo limitado y que en ningún caso puede suponer la extinción del mandato, como el Tribunal Constitucional ha afirmado de manera tajante ${ }^{2}$. Dejaremos fuera de nuestro estudio situaciones que provocan una suspensión de facto, no declarada, como la ausencia provocada por una enfermedad prolongada o por motivos personales de la persona representante (ibid.: 228).

En el caso de la suspensión disciplinaria, solo analizaremos aquella que supone la pérdida temporal de todos los derechos y facultades, dejando de lado el estudio de la que únicamente afecta a alguno de ellos, a pesar de que técnicamente también pueden considerarse supuestos de suspensión (Víboras Jiménez, 2001: 89).

Como puede imaginarse, la importancia de la suspensión reside no solo en la incidencia directa sobre el derecho de participación política del art. 23 $\mathrm{CE}$, sino que se extiende a la composición de la misma Cámara parlamentaria, dado que nuestro sistema no contempla la sustitución de la persona representante. De esta manera, cuando se acuerda la suspensión de un parlamentario o parlamentaria, se acaba incidiendo en la composición que la ciudadanía ha otorgado a las Cámaras, pudiendo alterarse así de manera artificial el proceso de adopción de decisiones tan relevantes como la investidura de la Presidencia del Gobierno, una eventual moción de censura o cuestión de confianza o la aprobación de los presupuestos (Presno Linera, 2009: 41).

Otra cuestión que requerirá nuestra atención es la extensión de los efectos de la suspensión de las prerrogativas parlamentarias, dada la diversidad presente en los ordenamientos parlamentarios autonómicos y la incidencia directa, otra vez, sobre el estatus de la persona representante, y de manera indirecta sobre la composición de la Cámara a la que pertenece.

\section{TIPOS DE SUSPENSIÓN EN FUNCIÓN DE LA CAUSA}

La suspensión puede ser consecuencia de un proceso judicial penal o traer causa en un procedimiento disciplinario previsto en el mismo

2 «Carece de fundamento la tesis de que el ejercicio de la función parlamentaria no admite interrupción alguna, de tal manera que toda suspensión en el desempeño del cargo debería llevar aparejada la extinción de la representación parlamentaria. Sea suficiente seńalar, al respecto, que el propio Reglamento de la Asamblea de Cantabria, en sintonía con lo dispuesto en los reglamentos del Congreso y del Senado, contempla expresamente la situación de suspensión de los Diputados en sus derechos y deberes parlamentarios por causas diversas, entre ellas precisamente, como antes quedó dicho, la de que una sentencia firme condenatoria lo comporte (art. 19.1 y 3 del Reglamento de Cantabria; cfr. Arts. 21.1 Reglamento del Congreso, y arts. 22, 101 y 102 Reglamento del Senado)»(STC 7/1992, de 16 de enero, FJ Tercero). 
reglamento parlamentario. A ello hay que sumar, como decíamos, la situación en que se encuentran las personas representantes que no han perfeccionado su cargo y, en consecuencia, no han adquirido la condición plena de parlamentario o parlamentaria.

\subsection{La situación de los representantes electos}

Los reglamentos parlamentarios someten la adquisición plena del cargo parlamentario a una suerte de condición suspensiva: el cumplimiento de determinados requisitos que, con algún matiz, se traducen en la obligación de presentar o cumplimentar alguna información sobre bienes y actividades que podrían resultar incompatibles y en el necesario acatamiento de la Constitución y del respectivo estatuto de autonomía en el caso de las comunidades autónomas. Se trata de una situación que, sin ser del todo equivalente a la de suspensión, porque en puridad no se produce un paréntesis en el disfrute de los derechos, deberes y prerrogativas de los diputados, presenta algunas concomitancias. En la doctrina se ha considerado desde una especie de congelación sine die del mandato parlamentario (Caamaño, 1991: 221) hasta una suerte de sanción que se impone por el incumplimiento de determinados deberes (Del Pino Carazo, 2006: 238).

Esta situación, que se prolonga hasta tanto el representante cumpla con los requisitos exigidos, es tratada de manera diversa en los distintos reglamentos parlamentarios, que en su gran mayoría establecen que pasado un plazo máximo de tres sesiones sin que se haya perfeccionado la condición de parlamentario, la misma queda suspendida en el ejercicio de sus derechos y deberes e incluso, en algunos ordenamientos, de sus prerrogativas. Sin embargo, la ligereza con que algunos reglamentos suspenden las prerrogativas de sus representantes requiere de un análisis detallado y separado de la cuestión. Lo veremos más adelante.

En el Reglamento del Congreso, los requisitos necesarios para la adquisición de la condición plena de diputado o diputada son los siguientes:

— Presentación de la credencial expedida por la Administración electoral en la Secretaría General.

- Presentación de la declaración de actividades en los términos previstos en la Ley Orgánica de Régimen Electoral General.

- Promesa o juramento de acatar la Constitución en la primera sesión plenaria a que se asista.

El art. 20.2 RC establece que «los derechos y prerrogativas serán efectivos desde el momento mismo en que el Diputado sea proclamado electo. Sin 
embargo, celebradas tres sesiones plenarias sin que el Diputado adquiera la condición de tal, conforme al apartado precedente, no tendrá derechos ni prerrogativas hasta que dicha adquisición se produzca».

Diversa es la regulación del Senado, prevista en el art. 12 RS, y que establece que "hasta tanto no hayan perfeccionado su condición, los Senadores electos y los designados por las Comunidades Autónomas no devengarán derechos económicos ni podrán participar en el ejercicio de las funciones constitucionales de la Cámara».

El Tribunal Constitucional ha avalado expresamente esta regulación al considerar que "se limita a formalizar el deber positivo de acatamiento que contiene la Constitución, de la que deriva directamente como un requisito, al ser inherente al cargo, el deber de que se trata ${ }^{3}$.

Los reglamentos parlamentarios autonómicos siguen el modelo del Congreso en su gran mayoría, y establecen que pasadas tres sesiones sin que se haya tomado posesión se suspende a la persona representante de tal condición. Es el caso de Madrid ${ }^{4}$, Murcia ${ }^{5}$, Extremadura ${ }^{6}$, Aragón $^{7}$, Canarias ${ }^{8}$, Cantabria $^{9}$, Galicia ${ }^{10}$, Baleares ${ }^{11}$, Andalucía ${ }^{12}$, Castilla y León ${ }^{13}$, La Rioja ${ }^{14}$ y Asturias $^{15}$.

No se establece esta determinación temporal de tres sesiones, ni ninguna otra, en los casos de Castilla-La Mancha ${ }^{16}$, Navarra ${ }^{17}$, País Vasco ${ }^{18}$, Valencia $^{19}$ yCataluña ${ }^{20}$.

STC 101/1983, de 18 de noviembre, F. J. Tercero.

Art. 12.3 Reglamento de la Asamblea de Madrid.

Art. 10.2 Reglamento de la Asamblea de Murcia.

Art. 16.1 Reglamento de Extremadura.

Art. 24.2 Reglamento de Aragón.

Art. 10.3 Reglamento del Parlamento de Canarias.

Art. 6.2 Reglamento del Parlamento de Cantabria.

Art. 7.2 Reglamento del Parlamento de Galicia.

Art. 8.2 Reglamento del Parlamento de las Islas Baleares.

Art. 5.2 Reglamento del Parlamento de Andalucía.

Art. 5.2 Reglamento de las Cortes de Castilla y León.

Art. 10.2 Reglamento del Parlamento de La Rioja.

Art. 8.2 Reglamento del Parlamento de Asturias.

Art. 7.3 Reglamento de Castilla-La Mancha.

Art. 26.3 Reglamento del Parlamento de Navarra.

8 Art. 9 Reglamento del Parlamento del País Vasco.

9 Art. 8.2 Reglamento de las Cortes Valencianas.

20 Art. 23.2 Reglamento del Parlamento de Cataluńa. 
Esta diferenciación no sería relevante para los efectos de la suspensión si no fuera porque algunos reglamentos entienden que pasados esos tres plenos sin perfeccionar su condición de representantes, se suspenden no solo derechos y deberes, sino además las prerrogativas parlamentarias, como veremos enseguida.

A mi juicio, esto plantea algunas dudas. En primer lugar, las prerrogativas se hacen efectivas desde el momento de la elección de la persona representante, no desde el perfeccionamiento de su condición a través del cumplimiento del acatamiento y los otros requisitos ${ }^{21}$. Solo esta interpretación es acorde con la finalidad de las prerrogativas, que no son privilegios procesales de los parlamentarios, sino que pretenden salvaguardar el ejercicio de la función parlamentaria.

En los reglamentos parlamentarios autonómicos encontramos regulaciones diversas: las que establecen de manera explícita que la suspensión afecta a las prerrogativas ${ }^{22}$, aquellos que no lo hacen ${ }^{23} y$ los que no especifican nada en cuanto a los efectos de la suspensión (Navarra, País Vasco y La Rioja). Como puede observarse, los reglamentos parlamentarios que optan por extender el alcance de la suspensión de las prerrogativas parlamentarias establecen el límite temporal de tres sesiones sin perfeccionar la condición de representante, por lo que distinguen entre las dos situaciones. Un poco más abajo retomaremos esta cuestión.

\subsection{Suspensión que trae causa en un proceso judicial}

La suspensión procedente de mandamiento judicial puede producirse en dos momentos procesales diferentes: en el curso de un procedimiento contra la persona representante o bien como consecuencia de una condena una vez terminado el proceso penal.

En este último caso tenemos que distinguir a su vez dos supuestos de naturaleza totalmente distinta: la suspensión que se acuerda en una sentencia

21 La STJUE dictada por la Gran Sala en el asunto C-502/19, de 19 de diciembre, que resuelve la cuestión prejudicial interpuesta por el Tribunal Supremo con motivo del proceso penal promovido contra Oriol Junqueras, establece de manera clara y taxativa esta conclusión: «Debe considerarse que una persona proclamada electa al Parlamento Europeo ha adquirido, por este hecho y desde ese momento, la condición de miembro de dicha institución, a efectos del artículo 9 del Protocolo sobre los privilegios y las inmunidades de la Unión, y goza, en este concepto, de la inmunidad prevista en el párrafo segundo del mismo artículo» (\$81).

22 Madrid, Murcia, Extremadura, Aragón, Canarias, Baleares, Andalucía, Castilla-León y Asturias.

23 Castilla-La Mancha, Valencia, Cantabria, Galicia y Cataluña. 
judicial como penay aquella que reconocen los reglamentos parlamentarios de manera prácticamente unánime como consecuencia de una sentencia que impide el ejercicio de la función parlamentaria. En este caso, no la decreta el poder judicial, sino la propia Cámara ante la evidencia de que el representante no podrá desempeñar su labor.

\subsubsection{La suspensión consecuencia de sentencia judicial}

El Código Penal español incluye en su tipología de penas tanto la inhabilitación absoluta como la inhabilitación especial y la suspensión para empleo o cargo público ${ }^{24}$. La inhabilitación y la suspensión operan de manera diferente. Como ha recordado el Tribunal Constitucional, «la suspensión de cargo público privará de su ejercicio al penado, así como a obtener otro de funciones análogas por el tiempo de la condena, pero no le priva del cargo, pues ese es el efecto de otra pena diferente: la inhabilitación absoluta o especial ${ }^{25}$.

La suspensión de cargo público, además de constituir pena principal en aquellos delitos que así lo tienen establecido, puede constituir pena accesoria tal y como establecen los arts. 55 y $56 \mathrm{CP}$ : de forma automática en las penas de prisión de diez años o superior y como posibilidad en los delitos que lleven aparejada una pena de prisión inferior ${ }^{26}$.

24 Art. 39 Código Penal. Son penas privativas de derechos:

a) La inhabilitación absoluta.

b) Las de inhabilitación especial para empleo o cargo público, profesión, oficio, industria o comercio, u otras actividades determinadas en este Código, o de los derechos de patria potestad, tutela, guarda o curatela, tenencia de animales, derecho de sufragio pasivo o de cualquier otro derecho.

c) La suspensión de empleo o cargo público.

d) La privación del derecho a conducir vehículos a motor y ciclomotores.

e) La privación del derecho a la tenencia y porte de armas.

f) La privación del derecho a residir en determinados lugares o acudir a ellos.

g) La prohibición de aproximarse a la víctima o a aquellos de sus familiares u otras personas que determine el juez o el tribunal.

h) La prohibición de comunicarse con la víctima o con aquellos de sus familiares u otras personas que determine el juez o tribunal.

i) Los trabajos en beneficio de la comunidad.

j) La privación de la patria potestad.

25 STC 7/1992, de 16 de enero, FJ Segundo.

26 «Art. 55. La pena de prisión igual o superior a diez años llevará consigo la inhabilitación absoluta durante el tiempo de la condena, salvo que ésta ya estuviere prevista como pena principal para el supuesto de que se trate. El Juez podrá además 
En la Ley Orgánica de Régimen Electoral General (en adelante, LOREG) no se contienen referencias a la suspensión de los diputados. Únicamente regula las causas de inelegibilidad e incompatibilidad, en las que conviene detenerse un momento. Con respecto a lo primero, el art. 6.2 de la LOREG establece entre las causas de inelegibilidad:

— Los condenados por sentencia firme a pena privativa de libertad, en el período que dure la pena.

- Los condenados por sentencia, aunque no sea firme, por delitos de rebelión, de terrorismo, contra la Administración pública o contra las instituciones del Estado cuando la misma haya establecido la pena de inhabilitación para el ejercicio del derecho de sufragio pasivo o la de inhabilitación absoluta o especial o de suspensión para empleo o cargo público en los términos previstos en la legislación penal.

Asimismo, las causas de inelegibilidad son también causas de incompatibilidad, por lo que los condenados a penas privativas de libertad, durante el tiempo que dure su condena no podrán desempeñar el cargo público ${ }^{27}$. Esto nos obliga a plantearnos una cuestión: los condenados por sentencia firme a pena de prisión inferior a la duración del mandato, ¿̇son suspendidos o cesan en el cargo? Según el mismo Tribunal Constitucional ha dicho, solo pueden resultar suspendidos, dado que el cese sería una limitación del derecho fundamental que no traería causa en la condena.

disponer la inhabilitación especial para el ejercicio de la patria potestad, tutela, curatela, guarda o acogimiento, o bien la privación de la patria potestad, cuando estos derechos hubieren tenido relación directa con el delito cometido. Esta vinculación deberá determinarse expresamente en la sentencia.

Art. 56.1. En las penas de prisión inferiores a diez años, los jueces o tribunales impondrán, atendiendo a la gravedad del delito, como penas accesorias, alguna o algunas de las siguientes: $1 .^{\circ}$ Suspensión de empleo o cargo público. $2 .^{\circ}$ Inhabilitación especial para el derecho de sufragio pasivo durante el tiempo de la condena. $3 .^{\circ}$ Inhabilitación especial para empleo o cargo público, profesión, oficio, industria, comercio, ejercicio de la patria potestad, tutela, curatela, guarda o acogimiento o cualquier otro derecho, la privación de la patria potestad, si estos derechos hubieran tenido relación directa con el delito cometido, debiendo determinarse expresamente en la sentencia esta vinculación, sin perjuicio de la aplicación de lo previsto en el art. 579 de este Código".

27 Art. 155 LOREG: «Las causas de inelegibilidad de diputados y senadores lo son también de incompatibilidad». 
Ciertamente, en la STC 7/1992, de 16 de enero, el Tribunal Constitucional destaca:

Aunque la pena de suspensión de cargo público implica siempre la imposibilidad de obtener otro de funciones análogas durante el tiempo de condena (art. 38 C.P.) y, por ello, constituye una causa de inelegibilidad en nuestro Derecho, en los términos expuestos en nuestras Sentencias 80/87 y 158/91, no puede admitirse la aplicación extensiva del art. 160 LOREG que propugnan las partes recurrida y coadyuvante, imponiendo la renuncia del escaño a todo aquél diputado que se vea sometido a una condena penal generadora de inelegibilidad, puesto que, ante el silencio de la ley electoral al respecto, no cabe la posibilidad de interpretar extensivamente la formulación legal de las causas de inelegibilidad (STC 28/1986), sino que es preciso proceder a una integración a partir de otros preceptos aplicables con arreglo al sentido de la institución y de los fines que procura (STC 51/1985) ${ }^{28}$.

Si la condena de suspensión se produce por rebelión o terrorismo, los efectos se producen aunque la sentencia no sea firme, como establece el art. 6.2.b) de la LOREG.

En consonancia, con esta regulación el Reglamento del Congreso establece en su art. 21.2 que «el diputado quedará suspendido en sus derechos, deberes y prerrogativas cuando una sentencia firme condenatoria lo comporte o cuando su cumplimiento implique la imposibilidad de ejercer la función parlamentaria».

De esta manera, el Reglamento del Congreso asume de manera automática que no solo la sentencia firme que lleva aparejada la suspensión del cargo público produce ese efecto, sino también la sentencia firme que imposibilite el ejercicio del cargo. Habrá que dilucidar qué se entiende por este segundo concepto, aunque parece lógico sostener que cualquier condena que comporte la pérdida de libertad deambulatoria del representante y, en consecuencia, la imposibilidad de asistir con normalidad a las sesiones, como sería la privación del derecho a residir o acudir a Madrid, sede de las Cortes Generales ${ }^{29}$, o la localización permanente, que puede obligar a la persona penada a permanecer en su domicilio o en lugar determinado fijado por la resolución judicial ${ }^{30}$. Incluso la pena de trabajos para la comunidad $^{31}$ en determinadas

28 STC 7/1992, de 16 de enero, FJ Tercero.

29 Art. 33.2. h. Ley Orgánica 10/1995, de 23 de noviembre, del Código Penal.

$30 \quad$ Art. 37.

31 Art. 33.3.1. 
circunstancias puede suponer la imposibilidad práctica de acudir a las sesiones. Pensemos que la configuración actual del sistema parlamentario exige la presencia física de la persona representante, en consonancia con la idea de que el Parlamento es un sitio en el que se delibera, se parlamenta y solo después de ello, se adoptan decisiones. Las posibilidades de participar de las decisiones parlamentarias sin concurrir de manera presencial son mínimas y además están tasadas para casos muy concretos, con una regulación que varía en función de que se establezca o no la posibilidad de delegar el voto, como ocurre en algunos Parlamentos autonómicos ${ }^{32}$, con una regulación no exenta de problemas (De Miguel, 2010: 150). Sin embargo, la Constitución prohíbe la delegación de voto en las Cortes Generales. Pero esa es otra cuestión.

$\mathrm{El}$ art. 21.2 RC establece que la suspensión prevista en este supuesto conlleva no solo la de derechos y deberes, sino también las prerrogativas. Eso nos lleva a sostener que si se iniciara un nuevo procedimiento penal contra la persona representante que ha sido suspendida en el ejercicio de su función, no cabría solicitar el suplicatorio, pues la suspensión motivada por estas causas conlleva también la de las prerrogativas, incluida, entendemos, la inmunidad. En consecuencia, podría ser detenido aunque lo fuera al margen de la flagrancia en la comisión de un delito y procesado sin necesidad de la solicitud de suplicatorio. En cuanto al aforamiento, cabe presumir que el diputado suspendido en virtud de sentencia judicial pierde tal garantía, por lo que es juzgado por el juzgado pertinente con arreglo a las leyes procesales.

Sin embargo, estas conclusiones que cabe extraer de la letra del Reglamento del Congreso podrían resultar contrarias a la Constitución al no considerar el fin último de las prerrogativas parlamentarias en tanto que garantías de la función parlamentaria que la persona representante desarrolla. Imaginemos que una persona representante resulta suspendida por un corto período de tiempo y en ese momento se inicia un procedimiento judicial contra ella motivado por cuestiones exclusivamente políticas, que es lo que la inmunidad con su exigencia de suplicatorio trata de evitar. ¿Podemos aceptar sin más que la suspensión se extiende a las prerrogativas? A mi juicio resulta, cuanto menos, constitucionalmente dudoso, dado que mantiene la condición de representante público, aunque en suspenso. Lo mismo cabría decir del aforamiento.

El Reglamento del Senado, por su parte, guarda silencio sobre este asunto, y regula únicamente la suspensión que se produce en el curso de un procedimiento penal, como veremos a continuación, por lo que no se suspende

32 Es lo que sucede en Andalucía, Cataluña, Extremadura, Navarra, País Vasco y Canarias. 
al senador o senadora condenada si la suspensión no está establecida como pena de manera expresa.

Los reglamentos parlamentarios autonómicos también han previsto la suspensión por causa de una sentencia judicial, aunque con notables diferencias entre ellos (Montaner, 2007: 317). Siguen el modelo del Reglamento del Congreso de los Diputados Andalucía ${ }^{33}$, Aragón ${ }^{34}$, Asturias ${ }^{35}$, Baleares ${ }^{36}$, Canarias $^{37}$, Cantabria ${ }^{38}$, Castilla-La Mancha ${ }^{39}$, Castilla y León ${ }^{40}$, Cataluña ${ }^{41} ;$ y con alguna singularidad Extremadura ${ }^{42}$, Galicia ${ }^{43}$, Madrid ${ }^{44}$, Navarra ${ }^{45}$, País $\operatorname{Vasco}^{46}$, La Rioja ${ }^{47}$ y Murcia ${ }^{48}$, que han previsto la suspensión no solo cuando la sentencia lo comporte expresamente, sino también cuando su cumplimiento implique la imposibilidad de ejercer la función parlamentaria.

En cambio, no lo prevé el Reglamento de las Cortes Valencianas, que establece que el diputado o diputada quedará suspendido en sus derechos y deberes parlamentarios «cuando así resulte de la condena impuesta por delito en sentencia firme y ejecutoria, en cuyo caso, el diputado o diputada quedará suspendido o inhabilitado para el ejercicio de la función parlamentaria durante el tiempo fijado en la sentencia y a partir del momento en que el juzgado o tribunal correspondiente comunique a Les Corts la fecha de inicio de cumplimiento de la pena ${ }^{49}$.

\footnotetext{
Art. 18 Reglamento del Parlamento de Andalucía.

Art. 25. c) Reglamento de las Cortes de Aragón.

Art. 24.2 Reglamento de la Junta General del Principado de Asturias.

Art. 9.2 Reglamento del Parlamento de las Illes Balears.

Art. 7.3 Reglamento del Parlamento Canario.

Art. 21.2 Reglamento del Parlamento de Cantabria.

Art. 8.1.c) Reglamento de las Cortes de Castilla-La Mancha.

Art. 17 Reglamento de las Cortes de Castilla y León.

41 Art. 25.1.b) establece que los diputados pueden ser suspendidos de sus derechos y deberes "por acuerdo del Pleno, adoptado por mayoría absoluta, si han sido condenados por sentencia firme a una pena de privación de libertad que imposibilite su asistencia a las sesiones plenarias».

42 Art. 16.1.3. ${ }^{\circ}$ Reglamento de la Asamblea de Extremadura.

43 Art. 20.2 Reglamento del Parlamento de Galicia.

44 Art. 13.1. d) Reglamento de la Asamblea de Madrid.

45 Art. 27.2 Reglamento del Parlamento de Navarra.

46 Art. 22.3 Reglamento del País Vasco.

47 Art. 11.2 Reglamento del Parlamento de La Rioja.

48 Art. 22.1 Reglamento de la Asamblea de Murcia.

49 Art. 9.3 Reglamento del Parlamento de las Cortes Valencianas.
} 
En consecuencia, en este caso, aunque la sentencia implique la imposibilidad de cumplimiento de los deberes parlamentarios, la suspensión de la persona condenada no se produce a pesar de que no puede ejercer sus derechos ni cumplir sus obligaciones como representante.

Hay un tercer supuesto de suspensión provocado por una sentencia judicial, previsto en el Reglamento de las Cortes de Aragón, que establece la posibilidad de suspender a la persona representante en casos de sentencia firme condenatoria por delito atendiendo a la gravedad de los hechos imputados y a la naturaleza de las penas ${ }^{50}$. En este caso, lo determinante no es la imposibilidad de acudir a las sesiones, sino una especie de sanción impuesta como consecuencia de la condena por un delito. A mi juicio, preceptos como este afectan al núcleo del derecho fundamental a la participación política del art. 23 CE. La suspensión debería estar prevista de manera tasada y determinada, limitando al máximo los supuestos en los que la Cámara tiene margen de actuación para acordarla.

En lo que respecta a las prerrogativas, únicamente cuatro ordenamientos parlamentarios establecen de manera expresa que la suspensión que trae causa en una sentencia judicial o, en la imposibilidad que supone esta para el ejercicio de la labor parlamentaria, se extiende no solo a los derechos y deberes, sino también a las mismas. Son Aragón ${ }^{51}$, Baleares ${ }^{52}$, Cantabria ${ }^{53}$ y La Rioja ${ }^{54}$. Ya hemos expresado nuestras dudas al respecto de los miembros de las Cortes Generales, que se hacen extensivas a los Parlamentos autonómicos aun cuando el alcance de las prerrogativas sea otro, dado que no aparecen comprendidas en el art. $71 \mathrm{CE}$, que se refiere exclusivamente a las Cortes Generales (Martínez Sospedra, 1995: 3). La finalidad, que es lo realmente importante aquí, es la misma y es la que hay que salvaguardar. Si se mantiene la condición de representante, aunque sea en suspenso, las prerrogativas deben mantenerse. A mi juicio, las prerrogativas se vinculan a la condición de representante y no a su efectivo ejercicio. Solo así se garantiza que cumplen la función que tienen encomendada y que no es otra que salvaguardar la integridad de la cámara parlamentaria. De acuerdo con esta finalidad, los reglamentos parlamentarios se extralimitan al considerar que las prerrogativas parlamentarias pueden ir

50 El art. 25.c) del Reglamento de las Cortes de Aragón permite suspender «en los demás casos de sentencia firme condenatoria por delito, si el Pleno de las Cortes así lo acordara por mayoría de 2/3 de los miembros de la Cámara, atendiendo a la gravedad de los hechos imputados y a la naturaleza de las penas».

51 Art. 25 Reglamento de las Cortes de Aragón.

52 Art. 9 Reglamento del Parlamento Balear.

53 Art. 21.2 Reglamento del Parlamento de Cantabria.

54 Art. 11.2 Reglamento del Parlamento de La Rioja. 
aparejadas al efectivo ejercicio de la función parlamentaria y no a la condición de representante.

\subsubsection{La suspensión decretada por el poder judicial en el transcurso de un procedimiento penal contra el representante: auto de procesamiento o equivalente, concesión de suplicatorio y prisión provisional}

La posibilidad de que en el curso de un procedimiento judicial penal se produzca la suspensión de cargo público fue introducida en el ordenamiento procesal penal con la Ley Orgánica 4/1988, de 25 de mayo, de Reforma de la LECr.

Desde entonces, el art. 384 bis de la LECr establece que "firme un auto de procesamiento y declarada la prisión provisional por delito cometido por persona integrada o relacionada con bandas armadas o individuos terroristas o rebeldes, el procesado que estuviere ostentando función o cargo público quedará automáticamente suspendido en el ejercicio del mismo mientras dure la situación de prisión». De esta manera, el art. 384 bis contempla la suspensión automática en el caso de que la persona titular del mandato parlamentario esté en prisión provisional por estar integrada o relacionada con bandas armadas o individuos terroristas o rebeldes. Esta alusión expresa a un tipo concreto de procedimientos demuestra cómo la regla general en el caso de los diputados y diputadas es la no suspensión del mandato hasta tanto se produzca la condena que eventualmente así lo establezca.

Con respecto a la exigencia de auto de procesamiento, tiene sentido porque «hasta entonces el reproche penal se mueve en el ámbito de la mera sospecha, y en ese terreno no puede tener consecuencias parlamentarias; de lo contrario, podría producirse un grave atentado contra la institución parlamentaria» (Del Pino Carazo, 2006: 256).

El precepto alude a la suspensión en el ejercicio del cargo, que solo podrá decretarse en el caso de los delitos aquí previstos - los cometidos por personas relacionadas o integradas en bandas armadas, terroristas o rebeldes - y firme el auto de procesamiento. La suspensión opera así de manera automática si se cumplen los requisitos y tiene que decretarla el juez que instruya el caso. El papel de las Cámaras debe limitarse, a mi juicio, a dar cumplimiento al mandamiento judicial, pero debería existir un pronunciamiento de la propia Cámara confirmándolo, aunque sin margen de maniobra para esta ${ }^{55}$. De la misma

55 Así ocurrió en la XIII legislatura en el caso de los cuatro diputados que se encontraban presos en el marco del juicio al procés: los señores Oriol Junqueras, Jordi Sànchez, Jordi Turull y Josep Rull. Y en el Senado, del señor Raúl Romeva. 
manera que sucede en el caso en el que la suspensión venga determinada por una sentencia judicial, las Cámaras tienen que limitarse a cumplir lo previsto en las resoluciones judiciales en estos casos (Lucas Murillo de la Cueva, 1990: 198).

Sin embargo, la suspensión de los parlamentarios procesados estaba prevista con anterioridad en los reglamentos parlamentarios de Congreso y Senado, fruto de la autonomía normativa de que gozan las Cámaras. En el primero, como una consecuencia insoslayable de la situación de prisión provisional. En el Senado, como una mera posibilidad.

$\mathrm{El}$ art. 21.2 RC establece como causa de suspensión en sus derechos y deberes de diputados y diputadas lo siguiente: «Cuando, concedida por la Cámara la autorización objeto de un suplicatorio y firme el Auto de procesamiento, se hallare en situación de prisión preventiva y mientras dure ésta».

Atendiendo a la suspensión producto de un mandamiento judicial, según el Reglamento del Congreso tendrían que producirse dos circunstancias: que la Cámara hubiera otorgado el suplicatorio para proceder contra el diputado o diputada, y que firme el auto de procesamiento, se encontrara en prisión preventiva. El RC establece que, en ese caso y mientras dure la situación de prisión, el o la representante queda suspendido. En consecuencia, los órganos de la Cámara únicamente tendrían que constatar que se den las condiciones previstas en el artículo, sin margen alguno de actuación en el caso de que así fuera.

Por su parte, el Reglamento del Senado destaca que en su art. 22.6 lo siguiente:

6. Concedido el suplicatorio y firme el auto de procesamiento, la Cámara podrá acordar por mayoría absoluta de sus miembros, y según la naturaleza de los hechos imputados, la suspensión temporal en la condición de Senador.

La sesión en que la Cámara se pronuncie sobre la procedencia de la suspensión será también secreta, y en ella solo se admitirán, en forma alternativa, dos turnos a favor y dos en contra, no concediéndose audiencia al Senador interesado.

En el supuesto de suspensión temporal a que este art. se refiere, la Cámara, en su resolución, podrá acordar la privación de la asignación del Senador implicado hasta su terminación.

De esta manera, el Reglamento del Senado circunscribe la posibilidad de suspender a los miembros del Senado únicamente al supuesto de concesión de un suplicatorio por parte de la Cámara, pero no lo hace de manera automática, como el Reglamento del Congreso. Por el contrario, se establece un procedimiento que requiere la mayoría absoluta para acordar y decretar esa suspensión. El Senado tiene así la potestad de decidir la no suspensión de un 
miembro que se encuentra en prisión provisional, aunque no pueda ejercer sus obligaciones.

En consecuencia, según los reglamentos del Congreso y del Senado, la suspensión acordada a resultas de un proceso judicial solo puede imponerse una vez concedido el suplicatorio por la misma Cámara. Si la Cámara no se ha pronunciado, no cabe la suspensión más que si se da el supuesto de hecho del art. 384 bis LEC.

En el caso en el que las acciones procesales se inicien estando vigente el mandato parlamentario, la secuencia procesal parece fácil de anticipar. Para iniciar el procesamiento se requiere el suplicatorio. Una vez concedido y firme el auto de procesamiento, la persona representante queda suspendida de manera automática si ese proceso conlleva la prisión provisional. En el caso del Senado, será la propia Cámara la que por mayoría absoluta decida si tras la concesión del suplicatorio y la firmeza del auto de procesamiento, procede o no la suspensión del miembro de la Cámara Alta.

Y, atendiendo a lo previsto en el art. 384 bis LEC, si un cargo público se encuentra en prisión provisional por los actos que se detallan, la suspensión es automática. Aunque siempre tendrá que haber un pronunciamiento de los órganos de gobierno del Congreso o del Senado que así lo declaren, a efectos de mero reconocimiento. Lo mismo cabría decir si hablamos de miembros de Cámaras autonómicas.

La aparente claridad de todo esto se complica cuando, como ha sucedido en el caso de los políticos catalanes juzgados y condenados por el Tribunal Supremo por el procés (Sentencia 459/2019, de 14 de octubre), los hechos descritos en el art. 384 bis son anteriores incluso a la fecha de elección como representantes de las Cortes Generales. En este caso, son muchas las preguntas que cabe hacer y que han llevado a resoluciones contradictorias de los actores implicados ${ }^{56}$, incluyendo un intercambio de pareceres bastante sorprendente

56 Como la más que cuestionada resolución de la Junta Electoral Central, de 29 de abril, que resuelve el Expediente 283/784, en respuesta a unas reclamaciones interpuestas por Ciudadanos-Partido de la Ciudadanía y el Partido Popular contra la candidatura de la coalición Lliures per Europa (JUNTS), solicitando que se proceda a la exclusión de los candidatos Sres. Puigdemont, Ponsati y Comín por entender que no reúnen la condición de electores. Aunque la causa principal alegada para negar este derecho fuera otra, uno de los motivos argumentados tiene que ver con la aplicación del art. 384 bis, considerando que no se puede ser elector si se está incurso en la situación descrita en este artículo. En concreto, se destaca que «la cualidad de elector del art. 6.1 de la LOREG no resulta compatible ni con la limitación de los derechos políticos a que alude el art. 384 bis de la LEC, ni con la situación a la que llegan aquellos que voluntariamente se han situado extramuros 
entre la Cámara Baja y el Tribunal Supremo sobre la procedencia o no de solicitar el suplicatorio.

El conflicto se ha saldado con la decisión del Supremo de no solicitar el suplicatorio para continuar el procesamiento de tres diputados y un senador y con la decisión de ambas Cámaras, por resoluciones de sus respectivas Mesas, de suspender de su cargo a los que están siendo juzgados en aplicación del art. 384 bis LEC. La no solicitud del suplicatorio se basa en el hecho de que el juicio oral ya había comenzado en la fecha de su elección. El Reglamento del Senado en su art. 22 establece que «los senadores no podrán ser inculpados ni procesados sin la previa autorización del Senado, solicitada a través del correspondiente suplicatorio. Esta autorización será también necesaria en los procedimientos que estén instruyéndose contra personas que, hallándose procesadas o inculpadas, accedan al cargo de Senador». La letra del Reglamento circunscribe así la solicitud de suplicatorio a los momentos previos a la apertura del juicio oral. El Reglamento del Congreso, en cambio, se limita a reproducir el precepto constitucional, destacando que «durante el período de su mandato, los Diputados gozarán asimismo de inmunidad y solo podrán ser detenidos en caso de flagrante delito. No podrán ser inculpados ni procesados sin la previa autorización del Congreso». En mi opinión, esta interpretación no es la que mejor se acomoda a la finalidad de las prerrogativas que, recordemos, no es otra que proteger la integridad de la propia Cámara.

Otra de las cuestiones que dilucidar es si la suspensión de un cargo público anterior afecta y, si así es, de qué manera a las personas que acceden a otro cargo representativo estando suspendidos de uno anterior. En esta situación se accede al nuevo cargo de manera plena una vez que se hayan formalizado los requisitos exigidos para el perfeccionamiento de la condición de representante, y si se dieran las circunstancias para una suspensión, habría que declararla de nuevo. Es el caso de miembros del Parlamento catalán que se hallaban suspendidos y que accedieron a las Cortes Generales en las elecciones del 28 de abril de 2019. A mi juicio, el acceso al cargo de diputado o senador de un representante suspendido del ejercicio de su anterior mandato no supone la continuación de la misma, sino que habrá que estudiar si se dan

del ordenamiento jurídico español y de la acción de la justicia, lo que les impide no solo votar en España para evitar la detención, sino que tampoco tienen regularizada su situación, en el censo de electores residentes ausentes que viven en el extranjero (art. 31 de la LOREG), para poder votar fuera de España». Con independencia de otros asuntos que se entremezclan, esta resolución, que ya ha sido corregida en sede judicial, aplica el art. 384 bis para negar la condición de elector a personas que no han sido privadas de sus derechos de participación política. 
los supuestos previstos en el 384 bis o en los reglamentos respectivos y procede, en consecuencia, una nueva suspensión.

En el caso de los Parlamentos autonómicos, únicamente cuatro de ellos no reconocen la suspensión por esta causa en su reglamento parlamentario ${ }^{57}$, mientras que la mayoría prevén la suspensión por el procesamiento de la persona representante básicamente mediante dos modelos.

El primero de ellos, concede al Pleno por mayoría absoluta la decisión última sobre la suspensión, una vez decretado el procesamiento del parlamentario. Es el caso de Asturias (art. 24,1b RP), Baleares (art. 9.1.2 RP), Cataluña (art. 18.1a) RP) y País Vasco (art. 22.2 RP). En todos ellos menos en Baleares se destaca que habrá que atender a la naturaleza de los hechos imputados, recalcándose así el carácter no reglado de la suspensión, que se decide en Pleno.

El otro grupo estaría conformado por aquellos reglamentos que establecen la suspensión de manera automática siempre y cuando concurran dos requisitos: procesamiento, que algunos reglamentos exigen que sea firme, y prisión provisional. Es el caso de Cantabria (art. 21.1b RP), Extremadura (art. 16.1.2 RP), Madrid (art. 13.1c RP), Navarra (art. 27.3 RP), Valencia (art. 9.2 RP), Canarias (art. 7.2 RP) y La Rioja (art. 11.2 RP).

Una peculiaridad presenta el caso de Aragón, en el que el Pleno de la Cámara decide por dos tercios en el caso de que haya decretada prisión provisional contra un representante y sea firme el auto de procesamiento, aunque siempre atendiendo a la naturaleza de los hechos (art. 5.b RP).

En Castilla-La Mancha, por su parte, la suspensión puede ser acordada por el Pleno de la Cámara por mayoría de tres quintos cuando firme el auto de procesamiento conlleve prisión preventiva, atendida la naturaleza de los hechos imputados (art. 8.1b RP).

A mi juicio, si ya plantea problemas la suspensión decretada en el caso del procesamiento de la persona parlamentaria que se encuentra en prisión provisional, muchos más presenta la opción de que sea el Pleno el que decida algo tan relevante y que puede afectar al juego de mayorías, como la suspensión de uno de sus miembros. Creo que la suspensión nunca debería quedar en manos de las eventuales mayorías presentes en una Cámara.

\subsection{La suspensión disciplinaria}

La suspensión se ha extendido en nuestros ordenamientos parlamentarios como forma de sanción a los diputados ante conductas consideradas

57 Andalucía, Castilla y León, Galicia y Murcia. 
especialmente graves, como portar armas en el recinto parlamentario o alterar gravemente el desarrollo de las sesiones.

De esta manera, la autonomía parlamentaria permite que, en aplicación de las normas de disciplina contenidas en los reglamentos, uno o varios miembros del Parlamento puedan ver como sus derechos resultan afectados o, mejor dicho, limitados sin necesidad de que un juez lo determine. Y únicamente el Tribunal Constitucional, vía amparo, podrá restablecerlos en sus derechos si hubieran sido indebidamente cercenados.

La suspensión constituye una sanción de especial dureza que no tiene referente en nuestro entorno cultural más cercano. Como ha destacado Montaner Salas (2007: 312), «la medida de suspensión del mandato parlamentario que contemplan los reglamentos parlamentarios espańoles no guarda parangón con las medidas disciplinarias que suelen contemplarse en los sistemas parlamentarios de nuestro entorno más próximo». De hecho, en dichos regímenes la suspensión en el ejercicio de la función parlamentaria constituye una sanción de extraordinaria gravedad, que podría deberse a la trasposición del término suspensión que recoge como sanción las Standing Orders de la Cámara de los Comunes y que, a pesar del término, suspension, no suponen más que la privación de determinadas funciones, pero no de la "condición de parlamentario, a la que, salvo sentencia judicial, nadie puede afectar, una vez que los electores la crean» (Garrorena Morales, 1995: 4166).

Sea como fuere, lo cierto es que la suspensión como medida disciplinaria aparece en nuestro derecho parlamentario de manera unánime. El Reglamento del Congreso distingue entre la privación de alguno o todos los derechos reconocidos en los arts. 6 a 9 RC, regulada en el art. 99 RC y la situación de suspensión, regulada en el art. 101.

Según el art. $99 \mathrm{RC}$, los diputados podrán ser privados de alguno o todos los derechos reconocidos en los arts. 6 a 9 del Reglamento del Congreso ${ }^{58}$ cuando de forma notoria o reiterada dejaren de asistir a las sesiones del Pleno o comisiones o cuando se quebrantare el deber de secreto. Este último supuesto puede acabar comportando la suspensión en los casos más graves.

Por su parte, el art. 101 RC alude a la suspensión temporal del diputado, acordada por el Pleno de la Cámara, por razón de disciplina parlamentaria en una serie de supuestos:

58 Derechos de asistencia y voto al Pleno y a las comisiones de las que se forma parte; derecho a asistir a las comisiones de las que no se es miembro; derecho a formar parte al menos de una comisión; derecho a recabar informes, datos y documentos de las Administraciones públicas; derecho a percibir una asignación económica; derecho al abono de las prestaciones de la seguridad social, mutualidades o clases pasivas. 
— Cuando impuesta y cumplida sanción de las establecidas en el art. 99 $\mathrm{RC}$, persistiera en su actitud.

- Cuando la persona representante portara armas dentro del recinto parlamentario.

- Cuando la persona representante, tras ser expulsada del Salón de Sesiones, se negara a abandonarlo.

- Cuando incumpliera lo previsto en el art. $17 \mathrm{RC}$, e invocaran o hicieran uso de su condición de parlamentarios para el ejercicio de actividad mercantil, industrial o profesional.

La propuesta de suspensión corresponde a la Mesa en los tres primeros supuestos y a la Comisión del Estatuto en el cuarto, y debe ser acordada por el Pleno en sesión secreta.

En todo caso, conviene recordar que la suspensión por razón de la disciplina parlamentaria se extiende a los derechos y deberes, pero no a las prerrogativas, según establece de manera expresa el art. $21 \mathrm{RC}$.

El Reglamento del Senado, por su parte, establece en el art. 101.3 que "cuando el Senador a quien se le impusiere la sanción de abandonar el salón de sesiones se negare a atender el requerimiento, el Presidente adoptará las medidas pertinentes para hacer efectiva su expulsión y acordará su suspensión en el ejercicio de la función parlamentaria en el plazo máximo de un mes».

Por su parte, el art. 102 RS prevé la suspensión de la condición de senador al que portara armas en el recinto del Palacio del Senado en el plazo máximo de un mes, período que puede ser superior si se exhiben las armas durante una sesión parlamentaria ${ }^{59}$.

59 «Art. 102. 1. Los Senadores no podrán portar armas en el recinto del Palacio del Senado. El que contraviniere dicha prohibición podrá ser suspendido en la función parlamentaria por la Mesa durante un plazo máximo de un mes. En todo caso, el Senador que exhiba o haga uso de un arma blanca o de fuego durante el curso de una sesión será expulsado en el acto del salón de sesiones y suspenso en la función parlamentaria durante un mes como mínimo, sin perjuicio de que la Cámara, previa propuesta de la Mesa o cincuenta Senadores, amplíe o agrave el correctivo con un máximo de un año. Esta ampliación o agravación le será propuesta al Senado en la sesión inmediata a aquélla en que se produzca el incidente, previa audiencia del inculpado ante la Mesa. 2. El mismo correctivo de suspensión durante un mínimo de un mes y un máximo de un año, y por igual tramitación, se impondrá al Senador que agrediere a otro Senador o a alguno de los miembros del Gobierno durante el curso de una sesión. 3. En tales supuestos, hecha la consulta de agravación a la Cámara, no se permitirá más que un discurso de explicación o de defensa de otro Senador en representación del inculpado, durante veinte 
Los reglamentos parlamentarios autonómicos siguen el modelo previsto en el Congreso de los Diputados, distinguiendo entre la suspensión de uno o varios derechos y la suspensión temporal de la condición de diputado, que es la que a nosotros interesa. Esta última sanción es calificada de múltiples formas, aunque aludiendo siempre a la misma realidad: la suspensión de la condición de diputado, del ejercicio de las funciones parlamentarias, de los derechos y deberes del diputado, incluso de exclusión temporal de la Cámara, en función del reglamento parlamentario.

A pesar de las distintas fórmulas empleadas, se trata de la misma figura: la suspensión temporal de los derechos y deberes que lleva aparejada la condición de representante en respuesta a una conducta tipificada como sanción en el reglamento parlamentario. El procedimiento varía en función de cada ordenamiento.

El Tribunal Constitucional se ha ocupado de esta cuestión en varias ocasiones, dado que el recurso de amparo del art. 42 LOTC es la única vía para recurrir la posible violación de un derecho fundamental por parte de la persona representante sancionada ${ }^{60}$.

En cuanto a la extensión a las prerrogativas de la suspensión, únicamente el RP de Aragón establece esta consecuencia, mientras que el de Castilla-La Mancha guarda silencio sobre los efectos. En todos los demás casos se habla expresamente de suspensión en derechos y deberes.

\section{SUSPENSIÓN Y PRERROGATIVAS PARLAMENTARIAS}

A lo largo de todo el texto se ha ido haciendo referencia dispersa a la extensión de la suspensión de las prerrogativas parlamentarias de la persona representante. Más allá del estudio concreto de la regulación parlamentaria que aplicar, conviene no perder de vista la finalidad última de las prerrogativas, que en palabras del Tribunal no constituyen un privilegio del parlamentario:

Estas dos prerrogativas, aunque tienen distinto contenido objetivo y finalidad específica, como más adelante expondremos, encuentran su fundamento en el

minutos como máximo, y el Senado resolverá sin más trámite. El incidente será tramitado en sesión secreta. 4. Las suspensiones a que se refiere el presente art. comprenderán siempre la pérdida de la parte proporcional correspondiente a la retribución global del Senador objeto de la corrección».

60 AATC 1227/1988, de 7 de noviembre, y 334/1993, de 10 de noviembre; SSTC 136/1989, de 19 de julio; 7/1992, de 16 de enero; 169/1995, de 20 de noviembre; 129/2006, de 24 de abril; 192/2011, de 12 de diciembre, y 78/2016, de 31 de mayo. 
objetivo común de garantizar la libertad e independencia de la institución parlamentaria, y en tal sentido son complementarias. Al servicio de este objetivo se confieren privilegios, no como derechos personales, sino como derechos reflejos de los que goza el parlamentario en su condición de miembro de la Cámara legislativa y que solo se justifican en cuanto son condición de posibilidad del funcionamiento eficaz y libre de la institución —ATC 526/1986- y que, en la medida en que son privilegios obstaculizadores del derecho fundamental citado, solo consienten una interpretación estricta - STC51/1985-, tanto en el sentido lógico de sujeción a los límites objetivos que les impone la Constitución, como en el teleológico de razonable proporcionalidad al fin que responden, debiendo rechazarse en su consecuencia, todo criterio hermenéutico permisivo de una utilización injustificada de los privilegios, que conduzca a un resultado de privación, constitucionalmente ilícita, de la vía procesal pertinente prevista en la Ley ${ }^{61}$.

En este sentido y, a pesar de que las prerrogativas parlamentarias constituyen un privilegio procesal y como tal tienen que ser interpretadas de manera restrictiva, no podemos perder de vista el fin que persiguen: el correcto funcionamiento del Parlamento cuya composición no puede verse alterada de manera artificial porque ello podría acabar adulterando la formación de voluntad del órgano legislativo tal y como lo conformó la elección popular. Solo desde este prisma tienen sentido las prerrogativas y pueden compatibilizarse con valores tan relevantes como la justicia, la igualdad o el derecho a la tutela judicial efectiva (Fernández Segado, 2011: 72).

Como hemos ido analizando en las páginas precedentes, la regulación de los distintos ordenamientos parlamentarios es diversa en función de la causa de la suspensión, así como diversos son sus efectos.

En el caso de la suspensión que es consecuencia de una sanción, es decir, del ejercicio de la potestad disciplinaria que los reglamentos parlamentarios recogen, la regla general es la no extensión a las prerrogativas parlamentarias, con una única excepción ${ }^{62}$. Ciertamente, con independencia de la valoración que nos merezca la posibilidad de imponer sanciones tan duras por cuestiones de disciplina y de los problemas que su ejercicio ha planteado ante el Tribunal Constitucional, nos parece que en ningún caso una sanción impuesta por los órganos de la Cámara puede conllevar la suspensión de las prerrogativas parlamentarias. Parece que se olvida que las prerrogativas no se reconocen como privilegio de la persona representante, sino como garantía de la institución parlamentaria.

61 STC 243/1988, de 19 de diciembre, FJ Tercero.

62 Art. 5 Reglamento de las Cortes de Aragón. 
En el caso de la no adquisición de la condición plena de representante por falta de cumplimiento de los requisitos exigidos en los distintos ordenamientos, ya hemos visto cómo la regla general es la suspensión si pasadas tres sesiones plenarias ese perfeccionamiento no se produce. La constitucionalidad de la extensión de esta suspensión sui generis a las prerrogativas es algo que hay que evaluar.

A mi juicio, las prerrogativas parlamentarias se disfrutan desde la adquisición de la condición de representante electo, sin necesidad de esperar al momento de perfeccionamiento de esa condición ${ }^{63}$. Solo así se cumplen las importantes funciones que las prerrogativas están llamadas a preservar. Vincular su vigencia al cumplimiento de unos requisitos que a veces no dependen de la voluntad del elegido puede acabar incidiendo en la composición de la Cámara de la que el parlamentario forma parte, que es precisamente lo que el reconocimiento de las prerrogativas trata de evitar. Así aparece recogido en algunos reglamentos autonómicos, como son los de $\mathrm{Madrid}^{64}$, Murcia $^{65}$, Canarias ${ }^{66}$, Cantabria ${ }^{67}$, Galicia ${ }^{68}$, Baleares ${ }^{69}$, Castilla León ${ }^{70}$, La Rioja $^{71}$, Asturias ${ }^{72}$ y Andalucía ${ }^{73}$.

Siguen la estela del Reglamento del Congreso, que en el art. 20.2 RC establece que «los derechos y prerrogativas serán efectivos desde el momento mismo en que el Diputado sea proclamado electo». El Reglamento del Senado por su parte no precisa nada al respecto.

Distinta es la cuestión en el caso en que el ordenamiento parlamentario establezca la suspensión como consecuencia de la no adquisición de la condición plena de representante, pasadas tres sesiones plenarias.

En los reglamentos parlamentarios autonómicos encontramos regulaciones diversas, como las que establecen de manera explícita que la suspensión

63 Esta interpretación ha resultado avalada por el Tribunal de Justicia de la Unión Europea en la Sentencia de la Gran Sala de 19 de diciembre de 2019, dictada en el asunto C-502/19, que resuelve la cuestión prejudicial planteada por el Tribunal Supremo respecto a la vigencia de las prerrogativas de Oriol Junqueras.

64 Art. 12.3 Reglamento de la Asamblea de Madrid.

65 Art. 10.2 del nuevo Reglamento de la Asamblea de Murcia, aprobado en 2019.

66 Art. 10.3 Reglamento Parlamento de Canarias.

67 Art. 6.2 Reglamento del Parlamento de Cantabria.

68 Art. 7.2 Reglamento del Parlamento de Galicia.

69 Art. 8.2 Reglamento del Parlamento balear.

70 Art. 5.2 del Reglamento de las Cortes de Castilla y León.

71 Art. 10.2 Reglamento del Parlamento de La Rioja.

72 Art. 9.2 del Reglamento del Parlamento asturiano.

73 Art. 5.2 Reglamento del Parlamento andaluz. 
afecta a las prerrogativas - Madrid, Murcia, Extremadura, Aragón, Canarias, Baleares, Andalucía, Castilla León y Asturias-, las que no las incluyen entre sus efectos - Castilla-La Mancha, Valencia, Cantabria, Galicia y Cataluñay los que no especifican nada en cuanto a los efectos de la suspensión: Navarra, País Vasco y La Rioja.

El Reglamento del Congreso por su parte establece que el diputado «no tendrá derechos ni prerrogativas hasta que dicha adquisición se produzca» (art. 20.2 Reglamento del Congreso de los Diputados). El Reglamento del Senado en cambio únicamente señala que "hasta tanto no hayan perfeccionado su condición, los Senadores electos y los designados por las Comunidades Autónomas no devengarán derechos económicos ni podrán participar en el ejercicio de las funciones constitucionales de la Cámara» (art. 12.2 Reglamento del Senado).

A mi juicio, las regulaciones parlamentarias que extienden los efectos de la suspensión por no perfeccionamiento de la condición de representante a las prerrogativas, hacen una interpretación que no respeta su sentido y finalidad. Si la no adquisición plena de la condición de diputado pudiera suponer que no se disfruta de las prerrogativas parlamentarias, podría alterarse fácilmente la composición de la Cámara. Recordemos que en nuestro ordenamiento no está prevista la sustitución temporal de las personas representantes, por lo que la suspensión altera de manera automática la composición de la Cámara. La suspensión en el ejercicio de los derechos y facultades inherentes al cargo hasta tanto se subsane esa situación nos parece del todo pertinente y, lo que es más importante, constitucional. La extensión a las prerrogativas no encuentra fundamento, contraviniendo el espíritu constitucional que ha querido preservar al órgano parlamentario de las injerencias de cualquier agente externo que pudieran alterar el normal funcionamiento del mismo.

En lo que respecta a la suspensión judicial, únicamente cuatro ordenamientos parlamentarios autonómicos establecen de manera expresa que la suspensión que trae causa en una sentencia judicial o en la imposibilidad que supone esta para el ejercicio de la labor parlamentaria, se extiende no solo a los derechos y deberes, sino también a las prerrogativas. Son Aragón ${ }^{74}$, Baleares ${ }^{75}$, Cantabria $^{76}$ y La Rioja ${ }^{77}$. Ya hemos expresado nuestras dudas al respecto de los miembros de las Cortes Generales, que se hacen extensivas a los Parlamentos autonómicos aun cuando el alcance de las prerrogativas sea más limitado (Martínez Sospedra, 1995: 79).

\footnotetext{
74 Art. 25 Reglamento de las Cortes de Aragón.

75 Art. 9 Reglamento del Parlamento Balear.

76 Art. 21.2 Reglamento del Parlamento de Cantabria.

77 Art. 11.2 Reglamento del Parlamento de La Rioja.
} 
En el caso de las Cortes Generales, el Reglamento del Congreso establece de manera expresa la suspensión de las prerrogativas en el caso de la suspensión motivada por una sentencia judicial, tanto porque lo prevea de manera expresa como porque su cumplimiento impide el ejercicio de la labor parlamentaria $^{78}$. En el Senado, su Reglamento guarda silencio a este respecto.

\section{CONCLUSIONES}

El representante suspendido, como es lógico, no puede participar en ninguna de las actividades de la Cámara a la que pertenece, por lo que no puede asistir, ni mucho menos votar, en las sesiones parlamentarias, ya sea en Pleno o Comisión. Tampoco puede asistir a las sesiones de los órganos de los que eventualmente formara parte, como la Mesa o la Junta de Portavoces.

Otro efecto de la suspensión, según ha constatado la práctica parlamentaria más reciente, es el paso obligado del representante suspendido en sus atribuciones al Grupo Mixto, lo que provoca un efecto indirecto en la percepción de la subvención que reciben los grupos parlamentarios, dado que los parlamentarios suspendidos pasan a formar parte del Grupo Parlamentario Mixto sin que se les permita continuar formando parte de su grupo de procedencia, si es que lo tenían.

Esto supone que la suspensión de un representante despliega efectos no solo sobre su derecho fundamental a la participación política reconocido en el art. 23.2 CE, sino que acaba afectando al funcionamiento de la Cámara entera. Obviamente, en un sistema que no permite la sustitución del representante, la suspensión tiene efectos inmediatos sobre la composición de la Cámara de la que forman parte.

De hecho, en la XIII legislatura de las Cortes Generales, con motivo de la suspensión de cuatro diputados a raíz del proceso y posterior condena por el Tribunal Supremo en el caso del procès, saltó a la opinión pública el debate acerca de la posibilidad de modificar la mayoría necesaria para la investidura de la persona titular de la presidencia del Gobierno. A mi juicio, en ningún caso las mayorías exigidas pueden alterarse por motivo de la suspensión de alguno de sus miembros, aun cuando la doctrina se lo ha planteado (García-Escudero Márquez, 2010: 104). Es verdad que nuestra tradición reciente refuta

78 Art. 21.2 Reglamento del Congreso de los Diputados: «El Diputado quedará suspendido en sus derechos, prerrogativas y deberes parlamentarios cuando una sentencia firme condenatoria lo comporte o cuando su cumplimiento implique la imposibilidad de ejercer la función parlamentaria». 
esta interpretación, aunque la alteración fue por otros motivos muy concretos y excepcionales ${ }^{79}$. En el caso de la suspensión no parece justificado alterar las mayorías reforzadas previstas en la Constitución. A mi juicio, no hay argumentos suficientes para modificar las normas establecidas al efecto, máxime cuando se podría hacer un uso partidario de esa alteración en momentos especialmente relevantes, como la investidura de la presidencia del Gobierno o la aprobación de los presupuestos.

Todos los problemas que para la composición de la Cámara conlleva la suspensión podrían solucionarse estableciendo en la LOREG la sustitución temporal de representantes, como en otros ordenamientos jurídicos. Pero, comoquiera que está previsto, la suspensión es una figura jurídica que hay que interpretar de manera muy restrictiva, estableciendo todas las cautelas para su fijación. Lo exige así el respeto al derecho fundamental contenido en el art. 23 $\mathrm{CE}$, pero, sobre todo, el necesario respeto a la conformación de las Cámaras parlamentarias tal y como la quiso la voluntad popular en las elecciones.

\section{Bibliografía}

Caamaño Domínguez, F. (1991). El mandato parlamentario. Madrid: Congreso de los Diputados.

De Miguel Bárcena, J. (2010). La personalidad e indelegabilidad del voto y las reformas de los Reglamentos de los Parlamentos autonómicos. Revista Española de Derecho Constitucional, 90, 149-169.

Del Pino Carazo, A. (2006). La suspensión de los derechos de los parlamentarios. Corts: Anuario de Derecho Parlamentario, 17, 227-284.

Fernández Segado, F. (2011). La doctrina constitucional sobre las prerrogativas parlamentarias en España. Foro, Nueva época, 14, 13-72. Disponible en: https://doi.org/10.5209/rev_ FORO.2011.n14.38209.

García-Escudero Márquez, P. (2010). Voto parlamentario no presencial y sustitución temporal de los parlamentarios. Corts: Anuario de Derecho Parlamentario, 24, 81-114.

Garrorena Morales, A. (1995). El mandato representativo. En A. Montoya Melgar (dir.). Enciclopedia Jurídica Básica (tomo III, pp. 4168-4169). Madrid: Civitas.

79 Según puede comprobarse en el mismo Diario de Sesiones del Congreso de los Diputados, de 5 de diciembre de 1989, en el debate de investidura que se tenía que producir tras la celebración de elecciones la Presidencia interpretó el art. 20 RC considerando que la mayoría absoluta se alcanzaba con 167 diputados. El problema venía motivado por la anulación de los resultados electorales en las provincias de Pontevedra, Murcia y Melilla, lo que modificaba el número de miembros del Congreso de los Diputados en el momento, dado que tenían que repetirse las elecciones en las citadas provincias. 
Lucas Murillo de la Cueva, P. (1990). Sobre las inmunidades parlamentarias. Revista de Estudios Politicos, 69, 189-200.

Martínez Sospedra, M. (1995). Las prerrogativas de los parlamentarios territoriales: nota sobre la inmunidad limitada de los diputados de los Parlamentos autónomos. Corts: Anuario de Derecho Parlamentario, 1, 79-90.

Montaner Salas, C. (2007). Adquisición, suspensión y pérdida del mandato parlamentario. En F. Pau i Vall (coord.). Parlamento y Poder Judicial: XIII Jornadas de la Asociación Española de Letrados de Parlamentos (pp. 289-346). Madrid: Tecnos.

Presno Linera, M. A. (2009). La sustitución temporal de los representantes politicos. Madrid: Centro de Estudios Políticos y Constitucionales.

Víboras Jiménez, J. A. (2001). Los parlamentarios: acceso, condición, suspensión y pérdida. En Los sujetos de Derecho Parlamentario (pp. 73-106). Vitoria-Gasteiz: Parlamento Vasco. 